\title{
Ser-criança com asma: assumindo suas particularidades e lidando com restrições
}

Karina Machado Siqueira ${ }^{1}$, Isabela Cristine Ferreira Fernandes ${ }^{2}$, Juliana Chaves Araújo ${ }^{3}$, Ana Karina Marques Salge ${ }^{4}$, Thaíla Corrêa Castral ${ }^{5}$, Maria Alves Barbosa ${ }^{6}$

\footnotetext{
${ }^{1}$ Enfermeira, Doutora em Enfermagem. Professora Adjunta da Faculdade de Enfermagem da Universidade Federal de Goiás. Goiânia, GO, Brasil. E-mail: karinams.fen@gmail.com.

${ }^{2}$ Enfermeira, Mestre em Enfermagem. Discente do Programa de Pós-Graduação em Enfermagem da Faculdade de Enfermagem da Universidade Federal de Goiás. Goiânia, GO, Brasil. E-mail: isabela_cristine@hotmail.com.

${ }^{3}$ Acadêmica de Enfermagem da Faculdade de Enfermagem da Universidade Federal de Goiás. Goiânia, GO, Brasil. E-mail: juliana.chaves09@gmail.com.

${ }^{4}$ Enfermeira, Doutora em Patologia. Professora Associada da Faculdade de Enfermagem da Universidade Federal de Goiás. Goiânia, GO, Brasil. E-mail: anasalge@gmail.com.

${ }^{5}$ Enfermeira, Doutora em Enfermagem em Saúde Pública. Professora Adjunta da Faculdade de Enfermagem da Universidade Federal de Goiás. Goiânia, GO, Brasil. Email: thaccastral@gmail.com.

${ }^{6}$ Enfermeira, Doutora em Enfermagem. Professora Aposentada da Faculdade de Enfermagem da Universidade Federal de Goiás. Goiânia, GO, Brasil. E-mail: maria.malves@gmail.com.
}

Recebido: 21/02/2017.

Aceito: 20/10/2017.

Publicado: 31/12/2017.

Como citar esse artigo:

Siqueira KM, Fernandes ICF, Araújo JC, Salge AKM, Castral TC, Barbosa MA. Sercriança com asma: assumindo suas particularidades e lidando com restrições. Rev. Eletr. Enf. [Internet]. 2017 [acesso em: ____;19:a55. Disponível em: http://doi.org/10.5216/ree.v19.45572.

\section{RESUMO}

Estudo objetivou compreender como crianças com asma e suas famílias se percebem no convívio com a doença crônica e desenvolvem seus modos de enfrentamento e cuidado. Trata-se de pesquisa fenomenológica, realizada com cinco famílias de crianças com asma moderada ou grave. A coleta de dados ocorreu por meio de entrevistas, realizadas junto às crianças e seus familiares, durante visitas domiciliares, entre setembro de 2013 e janeiro de 2014. Sob a ótica da criança, ficou clara a dificuldade em lidar com medos, frustrações e constrangimentos relacionados à doença e ao tratamento, especialmente na escola. Os familiares enfatizaram restrições impostas na vida da criança e no ambiente familiar, além de referirem atitudes de cuidado que demonstram superproteção. Profissionais envolvidos na atenção a asma infantil precisam valorizar potencialidades da criança e autonomia da família nas ações de cuidado, favorecendo o convívio com a doença crônica e o empoderamento para o cuidar.

Descritores: Enfermagem Pediátrica; Criança; Asma; Família; Saúde Escolar.

\section{INTRODUÇÃO}

A asma é uma condição comum dentre as doenças crônicas respiratórias, que provoca inflamação das vias aéreas e limitação ao fluxo aéreo, levando à ocorrência de episódios de sibilância, dispneia, aperto no peito e tosse $\mathrm{e}^{(1-2)}$.

No Brasil, houve incremento significativo na prevalência de asma diagnosticada, variando entre $14,3 \%$ e $17,6 \%{ }^{(3)}$. Além disso, é uma das

principais causas de internação pelo Sistema Único de Saúde - SUS e motivo de busca por serviços de 
urgência e emergência ${ }^{(2)}$.

A baixa adesão ao tratamento pode ser responsável por maior impacto negativo da doença na vida do paciente, especialmente entre os mais jovens ${ }^{(4)}$. O controle da doença é obtido com ações bem sucedidas de manejo, destacando-se o conhecimento adquirido sobre a doença, os fatores desencadeantes, o uso dos inaladores, os sinais de controle e os sintomas que caracterizam as exacerbações ${ }^{(1,5-6)}$.

Devido à cronicidade, o tratamento da asma é prolongado e exige uma interação efetiva entre o paciente, os cuidadores e a equipe multiprofissional que presta assistência. No contexto infantil, a atenção interdisciplinar tem se mostrado efetiva para a melhora clínica da asma, devendo ser valorizada no processo $^{(7)}$. Além disso, intervenções focadas no cuidado centrado no paciente e na família, melhoram a satisfação e a comunicação durante as interações clínicas ${ }^{(8)}$.

É importante que a criança com asma, a depender de seu desenvolvimento cognitivo, seja incluída nos processos decisórios e envolvida nas discussões acerca do plano terapêutico proposto e das ações de cuidado a serem empreendidas. A opinião da criança merece ser valorizada, especialmente por assumir responsabilidades que favorecerão o automanejo eficaz da doença.

Alguns estudos tratam sobre o convívio da criança com as doenças crônicas e suas implicações para a família ${ }^{(9-11)}$, inclusive abordando alergias graves e asma ${ }^{(12)}$. No entanto, as percepções das próprias crianças, os modos de enfrentamento da família e o cuidado com a criança em sua integralidade ainda foram pouco explorados. Assim, buscou-se neste estudo, a compreensão de algumas facetas da essência do fenômeno Ser-criança com asma, com base nas percepções de quem convive com a doença e também daqueles que compartilham seu mundo-vida e seu cuidado.

Esta pesquisa teve por objetivo compreender como as crianças com asma e suas famílias se percebem no convívio com a doença crônica e empreendem seus modos de enfrentamento e ações para o cuidado.

\section{MÉTODO}

Estudo descritivo, fundamentado no método fenomenológico, desenvolvido com famílias de crianças com asma, acompanhadas em ambulatório especializado, em Goiânia-Goiás/Brasil.

A opção pela fenomenologia, enquanto referencial teórico-metodológico, baseou-se no entendimento de que ela preocupa-se com a essência do vivido e, ao mesmo tempo, se apresenta como uma ciência descritiva, rigorosa, que mostra e explicita os fenômenos tal como aparecem à consciência perceptiva ${ }^{(13)}$.

Seguindo a compreensão de que a criança com asma não é doente, mas vivencia uma situação de doença, sem deixar de exercer o seu ser-criança, tomamos como referência as compreensões de cuidado advindas do referencial de Martin Heidegger ${ }^{(14)}$. Segundo esse pensador, os modos de cuidado podem se dar em diferentes sentidos. Podem revelar a indiferença com o outro, configurando um modo negligente de cuidado, ou atingir duas possibilidades extremas, entendidas como modos positivos ${ }^{(15)}$.

Quanto aos modos positivos, o cuidado pode se dar como uma solicitude substitutiva ou antecipadora. Na primeira, toma-se o lugar do outro em suas ocupações, fazendo por ele, substituindo-o, impossibilitando 
que cuide de si mesmo. Já na segunda possibilidade, o cuidado não substitui o outro, mas se antecipa a ele, remetendo-o para sua responsabilidade ${ }^{(14)}$.

A coleta de dados foi realizada no período de setembro de 2013 a janeiro de 2014; participaram cinco famílias de crianças com asma moderada ou grave, com idades entre sete e dez anos. Para coleta de dados foram realizadas entrevistas, atentando-se para os pressupostos da pesquisa fenomenológica e utilizandose as seguintes questões norteadoras: Para vocês, como é cuidar de uma criança com asma? Como vocês percebem essa criança? Como o cuidado da criança com asma repercute na família de vocês?

No total, participaram da pesquisa cinco crianças e 13 familiares: cinco mães, um pai, dois padrastos, duas avós, duas tias, uma irmã. Foram considerados da família as pessoas indicadas por seus membros ${ }^{(16)}$.

Os familiares foram, inicialmente, contatados no ambulatório, no mesmo dia das consultas das crianças. Nesse momento, a pesquisadora responsável explicava os objetivos e a forma de condução do estudo e agendava a primeira visita domiciliar. Para cada família, foram realizadas duas visitas, respeitando os horários acordados.

As entrevistas foram realizadas com todos os membros da família presentes nas visitas domiciliares e apontados como partícipes do cuidado com a criança, que também participou das entrevistas, com liberdade de intervir e expressar suas opiniões. A partir das verbalizações iniciadas pelos familiares, a criança era incluída nas entrevistas e sua participação incentivada pela pesquisadora. Todas as crianças tiveram oportunidade de participar das entrevistas com suas famílias e expressar suas vivências.

Todas as entrevistas foram gravadas e, posteriormente, transcritas. Tiveram duração média de 40 minutos, em cada visita domiciliar. Como todos os membros da família presentes tiveram oportunidade de falar, ao mesmo tempo e em um mesmo ambiente, a pesquisadora procedia a transcrição das entrevistas se atentando para a distinção e identificação dos diferentes participantes.

O número de famílias participantes foi definido no decorrer da coleta de dados, segundo o critério da saturação dos dados, em que as convergências das informações coletadas sinalizavam para o encerramento da coleta de dados ${ }^{(17)}$.

Quanto às questões éticas, antes de iniciar a coleta, todos os participantes assinaram o "Termo de Consentimento Livre e Esclarecido". Além disso, a criança participante do estudo também assinou o "Termo de Assentimento", conforme recomendações vigentes no país.

O estudo é vinculado ao projeto de pesquisa "Impacto da condição crônica de saúde na vida de crianças e adolescentes asmáticos e de seus familiares", aprovado no Comitê de Ética em Pesquisa Médica Humana e Animal do Hospital das Clínicas da Universidade Federal de Goiás, protocolo CAAE 15563113.2.0000.5078.

A análise das descrições se baseou no "Método da Análise Qualitativa do Fenômeno Situado"(17). No primeiro passo da análise foi realizada uma leitura das descrições, buscando compreender o sentido do todo. Em seguida, optou-se por uma leitura mais atentiva, buscando identificar as unidades de significado. Durante a organização dessas unidades, apreendeu-se o sentido dos conteúdos e as convergências para a categorização ou construção dos temas. Nessa última etapa foram sintetizadas as unidades de significado 
com o intuito de se chegar à estrutura do fenômeno, isto é, à sua essência ${ }^{(17)}$.

Durante a análise as unidades de significado foram organizadas em duas categorias que sintetizaram os sentidos nelas contidos e convergiram para o tema que intitula este artigo - Ser-criança com asma: assumindo suas particularidades e lidando com restrições.

$\mathrm{Na}$ apresentação dos resultados foram utilizados trechos de falas dos participantes. Para manter o sigilo de identidade, códigos foram empregados, sendo que a primeira letra se refere à própria criança ou à representação da pessoa em relação a ela (C: criança, M: mãe, P: pai, PD: padrasto, I: irmã, A: avó, T: tia) e a segunda letra, seguida de um número, se refere a família do participante. Os números atribuídos às famílias seguiram a sua ordem de inclusão no estudo.

\section{RESULTADOS}

Particularidades da criança com asma: percepções próprias e de familiares

Os incômodos provocados pela doença, bem como os medos e angústias no enfrentamento das crises asmáticas se destacaram nos relatos de algumas crianças:

A asma? É assim, é ruim demais, eu tenho falta de ar, me atrapalha na escola e aqui em casa, quando eu vou dormir à noite, tenho medo de passar mal, num respirar mais. (Cf1)

Tem vez que fico pensando que eu vou dar crise e aí fico mais quieta, incomoda muito a falta de ar. Vai que eu paro de respirar, eu fico com medo... (Cf2)

Em alguns trechos de depoimentos das crianças emergiu o medo da morte, de forma velada, especialmente quando se referem ao medo de não conseguir respirar ou de sentir-se mal, bem como, de forma explícita, conforme depoimentos a seguir:

É mesmo, é muito ruim. Eu sinto dor de cabeça, falta de ar e dor aqui na barriga. Eu tenho medo, muito medo, medo de... de eu morrer. (Cf4)

Nossa, quando dá crise forte eu acho até que tem perigo de morrer. E se eu parar de respirar e morrer? (Cf5)

Para o tratamento medicamentoso da asma é necessário o uso de medicações que possuem formas específicas de apresentação e algumas particularidades para administrar. Algumas crianças afirmaram sentir vergonha e evitar utilizar os medicamentos na escola, notadamente os inaladores pressurizados dosimetrados, acoplados aos espaçadores. Tanto as crianças, quanto os familiares relataram essa dificuldade:

Quando precisa, eu acho melhor ir embora do que usar o remédio lá na escola. A bombinha eu até que uso, mas a garrafinha [espaçador artesanal] eu uso não, todo mundo acha esquisito. (Cf3)

Se for pra usar na escola eu tenho vergonha mesmo. Minhas colegas ficam é rindo de mim. Mas quando eu fico cansada eu fico quieta. Eu não uso o remédio lá não. (Cf2)

Ela sempre falava que não ia levar o remédio pra escola, tinha vergonha da doença, do remédio dela. (Af2) 
Também emergiram das descrições dos familiares percepções sobre as crianças. Relataram como as percebem no convívio com a doença e suas diferenças em relação a outras crianças. Essas diferenças se relacionaram, de modo especial, à possibilidade de, a qualquer momento, desencadearem crises asmáticas:

Tenho muito cuidado com ele, é diferente por causa da asma. Eu tenho outro filho, ele não tem asma. Com o G. é diferente por causa da respiração, da falta de ar. (Mf1)

Ela acha ruim, fica nervosa, mas ela é diferente nessas coisas, não adianta querer fazer tudo que as outras crianças faz porque pode ficar passando mal. (Af3)

As atitudes de proteção geram conflitos entre os familiares e discordâncias nas formas de perceber e lidar com a criança. A seguir, apresentaremos os discursos da avó e da mãe de uma mesma família, tomados como exemplo para evidenciar aspectos divergentes entre os familiares, no que se refere ao cuidado com a criança que tem asma:

Eu sempre tive dó dela porque é mais magrinha, vivia internada, direto ficava internada, vixe, sofria demais com isso. $A$ mãe dela é mais brava com ela, eu não dou conta de ser, tenho dó, já passou tanto sofrimento, tadinha. (Af2) Ela é difícil, é teimosa, é muito paparicada pela minha mãe, sempre foi. Tem dia que ela cisma de não usar o remédio, o da asma, e aí fica sem (...) Minha mãe defende, diz que eu preciso ter paciência porque ela é doentinha, eu acho que ela mima demais. (Mf2)

Alguns familiares ressaltaram a importância de considerar as particularidades da criança relacionadas à doença, mas tratando-a como qualquer outra pessoa:

Eu sempre tento olhar ele como uma criança normal. Sempre mostro para ele que ele não é diferente. Ele tem uma doença que pode conviver como as outras crianças. (Mf4)

O G. é esperto, ele não deixa se abater com a doença não. (PDf1)

Essa possibilidade de tratar a criança como outras da mesma faixa etária parece estar relacionada ao controle da asma. Em muitos casos, os familiares que participavam ativamente dos cuidados com a criança relacionaram a melhora com o tratamento e destacaram as possibilidades de ser criança no convívio com a doença:

Eu já deixo ele mais liberado. Agora é que eu estou mais assim. Porque quando eu cheguei lá no hospital, eu protegia demais. Tentava isolar ele mais. (Mf4)

A mãe dele é que sempre me lembra do que ele pode e do que não pode. Mas ele não tem passado mal, ele brinca, corre com os meus meninos e não ta passando mal não. (Pf5)

\section{O convívio com as restrições impostas pela doença e tratamento}

Habitualmente, as crianças com asma têm restrições nas atividades comuns à idade, como correr, nadar e andar de bicicleta. A justificativa dos cuidadores para essas limitações relaciona-se à exacerbação de sintomas, principalmente tosse e dispneia. Algumas falas expressam essa atitude:

Esses dias eu viajei, mas ela não foi, minha irmã não deixou, a gente tem medo dela passar mal, tossir, faltar o ar. (Tf3) A gente brinca de tudo, ele que cansa mais fácil, daí eu tenho medo de ele passar mal e não fico correndo, andando de 
bicicleta. Credo, se ele passar mal, dá falta de ar. (If5)

Eu fico de olho nele também, no fim de semana eu brinco com ele. Do jeito que pode, não corre muito, não brinca na poeira. (PDf1)

Os cuidadores também relataram a dificuldade das crianças em aderirem a algumas orientações dos profissionais de saúde, principalmente às voltadas ao controle de alérgenos e irritantes no ambiente, fatores que podem desencadear as crises asmáticas. Citaram o contato com poeira, bichos de pelúcia e sofá de pano.

Algumas coisas eu tirei bastante na casa, melhorou muito, mas ele gosta de brincar no quintal, na terra. Ele solta pipa, brinca de bola, lá na poeira. Que jeito que a gente não vai deixar também, né? (Mf6)

A L. gostava das bonecas velhas, isso eu tive que tirar. Ainda tem bicho de pelúcia, só um, mas tem. Você pode ver lá no quarto. Esse ela não deixou dar pra ninguém. (Mf2)

A mãe dela sempre fala pra não ficar demais no sofá. Mas ela gosta é de lá. O sofá tá velho mesmo. (Pf3)

Enfoque especial foi dado à limitação do contato com animais domésticos que possuem pelos ou penas. Também, houve queixa das próprias crianças, que referiram não seguir as orientações com rigor, conforme exemplificado a seguir:

Eu acho bom é brincar com meu cachorro, minha mãe fala que não pode, lá no hospital também, mas eu brinco.(Cf2) Minha mãe é engraçada, não quer que eu brinco com o P., ele gosta de correr atrás de mim, eu deixo. Minha tia também fica falando: deixa esse cachorro pra lá! O quê que tem a gente correr? Não tô pegando nele né? (Cf3)

As restrições relacionadas ao brincar e à prática de atividades físicas no espaço escolar foram, frequentemente, recordadas pelas crianças. Apesar dessas atividades não serem proibidas por profissionais de saúde, em alguns casos, sintomas podem ser exacerbados após esforço físico. Nos depoimentos as crianças relataram suas insatisfações:

Nossa, o que eu mais acho ruim é quando eu não posso brincar com minhas colegas. Quando eu fico cansada, aí, víxe, eu tenho que parar mesmo. Tenho medo de piorar e parar de respirar. (Cf3)

Quase não passo mal na escola não, só quando eu corro muito, jogo bola com as meninas, brinco de basquete. (Cf2) Tem vez que eu quero brincar com os meninos, mas, se eu tiver cansado, eu não dou conta de jogar bola não, aí eu paro toda hora. (Cf4)

\section{DISCUSSÃO}

Além das restrições físicas impostas com o intuito de prevenir crises asmáticas, as descrições feitas neste estudo revelaram preocupação e angústia em lidar com os sintomas. Sendo ressaltado, inclusive, o medo de morrer, tanto pelos familiares, quanto as próprias crianças.

Algumas crianças afirmaram temer a morte durante as crises asmáticas, quando podem sentir grave desconforto respiratório. Apesar da facticidade humana e a condição existencial de ser-para-a-morte, inerente ao existir humano ${ }^{(14)}$, a possibilidade de morte de uma criança sempre costuma ser negada. Neste estudo, ela se mostrou de forma velada nos depoimentos de seus familiares e, somente em algumas falas das crianças, pode-se observar explicitamente o medo de morrer.

Além de seus medos, as crianças falaram de frustrações e de situações de constrangimento no convívio 
com seus pares. Em diversos momentos citaram a vergonha no uso de medicamentos na escola, o que pode ser necessário, especialmente nas exacerbações dos sintomas.

A timidez parece estar relacionada à forma de apresentação dos medicamentos que, em muitos casos, são inaladores pressurizados dosimetrados, os quais requerem uso acoplado a um espaçador para melhor eficácia e redução de efeitos colaterais ${ }^{(2,18)}$. O uso desses inaladores, também conhecidos como sprays ou bombinhas, surge como denunciante da situação de doença. Há uma forte relação entre esse tipo de medicamento e a asma.

Ao sentirem vergonha no uso do medicamento, o tratamento pode ficar prejudicado e dificultar o controle da doença. Ações de educação voltadas para a criança devem ser empenhadas para que a adesão ao plano terapêutico seja atingida, pois o controle ineficaz da asma relaciona-se diretamente com a baixa utilização da medicação de manutenção e maior necessidade de uso das medicações de alívio ${ }^{(19-20)}$.

Em nosso estudo as crianças também ressaltaram o sentimento de exclusão e frustração por não se integrarem às brincadeiras e práticas de atividades físicas desenvolvidas no ambiente escolar. O convívio com a doença pode influenciar no cotidiano da escola e interferir no aprendizado e frequência escolar. Além disso, as crianças também enfrentam conflitos com os colegas e restrições durante as brincadeiras ou atividades físicas realizadas nesse ambiente $\mathrm{e}^{(21)}$.

Compreendendo que a escola representa um lugar importante no mundo-vida da criança, entende-se que ela deve ser alvo de ações mediadas por profissionais de saúde que atuam na atenção à asma infantil. Revisão sistemática mostrou que o acesso direto da enfermagem em escolas e outros serviços de saúde, bem como, a educação específica para a doença, resultou em melhoria do estado de saúde e do desempenho acadêmico de estudantes com doenças crônicas ${ }^{(22)}$.

No que se refere às percepções dos familiares sobre a criança com asma foram destacadas as diferenças em relação às demais crianças, ressaltando as particularidades da doença e as restrições necessárias ao manejo eficaz. Algumas atitudes de proteção são reconhecidas, pela própria família e crianças, como excessivas.

Essas atitudes parecem estar relacionadas ao constante estado de alerta dos familiares para a condição de saúde da criança portadora de uma doença crônica, especialmente nos casos em que podem ocorrer exacerbações graves, como a asma. Em estudo com pais de crianças com alergias graves, estes referiram viver constantemente em guarda e destacaram os diferentes tipos de limitações experimentadas pela família ${ }^{(12)}$.

O convívio com a doença crônica, especialmente aquelas em que ocorrem exacerbações graves, como a asma, podem levar a criança a viver com diferentes formas de limitações, além de fazer com que os familiares se sintam constantemente alertas para qualquer alteração no estado de saúde da criança.

As famílias e os profissionais de saúde devem estar atentos às atitudes de superproteção, pois podem se configurar como uma forma de cuidar denominada solicitude substitutiva, segundo o referencial Heideggeriano de cuidado $^{(9)}$, onde a criança deixa de ter autonomia e responsabilidade com seu estado de 
saúde. É interessante que o cuidado aconteça como solicitude antecipadora, onde é possibilitado ao outro assumir seus próprios caminhos ${ }^{(9)}$ e busca-se cuidar de modo atento, preocupando-se com o outro e visando sua liberdade ${ }^{(23)}$.

Apesar de ser um processo complexo, as crianças que convivem com doenças crônicas são capazes de se adaptar à situação de adoecimento e modificar os modos de enfrentamento, na medida em que superam adversidades. Ademais, possuem capacidade de reconhecer as restrições impostas em suas vidas e se responsabilizarem pelo seu tratamento ${ }^{(10)}$.

\section{CONCLUSÃO}

Os desvelamentos deste estudo colaboraram para a melhor compreensão de como a criança se percebe no convívio com a doença e é percebida por seus familiares. Destacou-se a dificuldade da criança em lidar com alguns medos, frustrações e situações de constrangimento relacionadas à doença e ao tratamento.

A escola emergiu como importante espaço de convivência para a criança, onde encontra com os colegas e realiza atividades típicas do cotidiano infantil. No entanto, também se mostrou como um ambiente onde ela se sente discriminada e excluída. Nesse sentido, recomenda-se que ações que envolvam a parceria entre a educação formal e os serviços de saúde sejam empreendidas, com o intuito de informar melhor os professores e alunos sobre a asma e suas repercussões na vida da criança. Assim, a escola pode tornar-se um ambiente de apoio para que a criança desenvolva formas efetivas de enfrentamento da situação crônica de adoecimento.

Os familiares da criança com asma percebem suas particularidades enquanto Ser-criança e destacam as restrições impostas pela doença. Reconhecem que algumas atitudes de proteção à criança são excessivas e fazem parte de suas ações de cuidado. Essas atitudes superprotetoras são comuns entre cuidadores de crianças que possuem algum tipo de doença crônica e se dão em um sentido claro de colaboração com a criança. Porém, apesar da intenção positiva, esse comportamento dos familiares pode ser prejudicial ao desenvolvimento da criança.

Em suas ações de cuidado, a família pode colaborar para que a criança reconheça as restrições, seus medos e frustrações e, ao mesmo tempo, desenvolva mecanismos efetivos de enfrentamento. Assim, apesar de conviver com uma doença crônica, a criança pode transcender essa condição e resgatar o seu Ser-criança, assumindo, de forma autêntica, suas possibilidades existenciais.

\section{REFERÊNCIAS}

1. Global Initiative for Asthma. Pocket guide for asthma management and prevention (for adults and children older than 5 years). A Pocket Guide For physicians and Nurses Update 2015 [Internet]. 2015. [acesso em: 31 dez. 2017]. Disponível em: http://ginasthma.org/wp-content/uploads/2016/01/GINA Pocket_2015.pdf. 
2. Sociedade Brasileira de Pneumologia e Tisiologia. Diretrizes da Sociedade Brasileira de Pneumologia e Tisiologia para o Manejo da Asma - 2012. J Bras Pneumol [Internet]. 2012 [acesso em: 31 dez. 2017];38 supl. 1:s1-46. Disponível em: http://www.jornaldepneumologia.com.br/pdf/suple_200_70_38_completo_versao_corrigida_04-09-12.pdf. 3. Solé D, Rosário Filho NA, Sarinho ES, Camelo-Nunes IC, Barreto BAP, Medeiros ML, et al. Prevalence of asthma and allergic diseases in adolescents: nine-year follow-up study (2003-2012). J Pediatr (Rio J) [Internet]. 2015 [acesso em: 31 dez. 2017];91(1):30-5. Disponível em: http://doi.org/10.1016/j.jped.2014.05.002.

4. Alith MB, Gazzotti MR, Montealegre F, Fish J, Nascimento OA, Jardim JR. Negative impact of asthma on patients in different age groups. J Bras Pneumol [Internet]. 2015 [acesso em: 31 dez. 2017];41(1):16-22. Disponível em: http://doi.org/10.1590/S1806-37132015000100003.

5. Stephan AMS, Costa JSD. Conhecimento sobre asma das mães de crianças acometidas pela patologia, em área coberta pelo Programa Saúde da Família. Rev Bras Epidemiol [Internet]. 2009 [acesso em: 31 dez. 2017];12(4):671-9. Disponível em:: http://doi.org/10.1590/S1415-790X2009000400016.

6. Olivera CMX, Vianna EO, Bonizio RC, Menezes MB, Ferraz E, Cetlin AA, et al. Asthma self-management model: randomized controlled trial. Health Educ Res [Internet]. 2016 [acesso em: 31 dez. 2017];31(5):639-52. Disponível em: http://doi.org/10.1093/her/cyw035.

7. Siqueira KM, Pereira GL, Bittencourt AL, Colodino CS, Fernandes ICF, Barbosa MA. Avaliação clínica de crianças e adolescentes asmáticos: relevância da atenção interdisciplinar. Rev. Eletr. Enf. [Internet]. 2015 [acesso em: 31 dez. 2017];17(3). Disponível em: http://doi.org/10.5216/ree.v17i3.29910.

8. Harper FWK, Eggly S, Crider B, Kobayashi H, Kathleen RN, Meert L, et al. Patient- and Family-Centered Care as an approach to reducing disparities in asthma outcomes in urban African American children: A review of the literature. $J$ Natl Med Assoc [Internet]. 2015 [acesso em: 31 dez. 2017];107(2):4-17. Disponível em: http://doi.org/10.1016/S00279684(15)30019-5.

9. Pedroso MLR, Motta MGC. Criança e família convivendo com a doença crônica: mesossistema em ligação com a vulnerabilidade programática. Texto Context - Enferm [Internet]. 2013 [acesso em: 31 dez. 2017];22(2):493-9.

Disponível em: http://doi.org/10.1590/S0104-07072013000200027.

10. Vieira SS, Dupas G, Ferreira NMLA. Doença renal crônica: conhecendo a experiência da criança. Esc Anna Nery [Internet]. 2009 [acesso em: 31 dez. 2017];13(1):74-83. Disponível em: http://doi.org/10.1590/S141481452009000100011.

11. Mazza VDA, Souza C, Estevão AR, Guimarães SL, Mercês NNA. Vivência de famílias de crianças e adolescentes submetidos ao Transplante de Células-Tronco Hematopoéticas. Rev. Eletr. Enf. [Internet]. 2016 [acesso em: 31 dez. 2017];18:e1193. Disponível em: http://doi.org/10.5216/ree.v18.40131.

12. Lagercrantz B, Persson $\AA$, Kull I. "Healthcare seems to vary a lot": A focus group study among parents of children with severe allergy. J Asthma [Internet]. 2017 [acesso em: 31 dez. 2017];54(7):672-8. Disponível em::

http://doi.org/10.1080/02770903.2016.1258079.

13. Capalbo C. Fenomenologia e Ciências Humanas. Aparecida: Idéias \& Letras; 2008.

14. Heidegger M. Ser e tempo, parte I. 15a ed. Schuback MSC, tradutor. Petrópolis: Vozes; 2005.

15. Fernandes MA. Do cuidado da fenomenologia à fenomenologia do cuidado. In: Peixoto AJ, Holanda AF. Fenomenologia do cuidado e do cuidar: perspectivas multidisciplinares. Curitiba: Juruá Editora; 2011. p. 17-32. 16. Wright LM, Leahey M. Enfermeiras e famílias: guia para avaliação na intervenção na família. 5a ed. Trad. Silvia Spada. São Paulo: Roca; 2012.

17. Martins J, Bicudo MAV. A pesquisa qualitativa em Psicologia: fundamentos e recursos básicos. 5a ed. São Paulo: Centauro; 2005.

18. Camargo JSO, Magalhães PB, Fernandes ICF, Ramalho WS, Costa LDC, Salge AKM, et al. Utilização e eficácia de espaçadores no tratamento farmacológico de pacientes asmáticos: uma revisão integrativa. Rev Enferm UERJ [Internet]. 2013 [acesso em: 31 dez. 2017];20(5):654-60. Disponível em: http://www.epublicacoes.uerj.br/index.php/enfermagemuerj/article/view/5966.

19. Marchioro J, Gazzotti MR, Nascimento OA, Montealegre F, Fish J, Jardim JR. Level of asthma control and its relationship with medication use in asthma patients in Brazil. J Bras Pneumol [Internet]. 2014 [acesso em: 31 dez. 2017];40(5):487-94. Disponível em: http://doi.org/10.1590/S1806-37132014000500004.

20. Urrutia-Pereira M, Avila J, Solé D. The Program for the Prevention of Childhood Asthma: a specialized care program for children with wheezing or asthma in Brazil. J Bras Pneumol [Internet]. 2016 [acesso em: 31 dez. 2017];42(1):42-7. Disponível em: http://doi.org/10.1590/S1806-37562016000004480. 
21. Borba RIH, Ribeiro CA, Ohara CVS, Sarti CA. O mundo da criança portadora de asma grave na escola. Acta Paul Enferm [Internet]. 2009;22(esp.):921-7. Disponível em: http://doi.org/10.1590/S0103-21002009000700015.

22. Leroy ZC, Wallin R, Lee S. The Role of School Health Services in Addressing the Needs of Students With Chronic Health Conditions. J Sch Nurs [Internet]. 2017 [acesso em: 31 dez. 2017];33(1):64-72. Disponível em: http://doi.org/10.1177/1059840516678909.

23. Bicudo MAV. A fenomenologia do cuidar na educação. In: Peixoto AJ, Holanda AF, organizadores. Fenomenologia do cuidado e do cuidar: perspectivas multidisciplinares. Curitiba: Juruá Editora; 2011. p. 85-91. 